\title{
Using Shakespeare Drama to Foster Student Engagement and Language Learning
}

\author{
Vikineswaran A. Maniam, Lisa Su Li Kwan, Hansini Thedchanamoorthy, \\ Phawani Vijayaratnam, Daniel Tan Eng Keng, Lee Ling Sin
}

\begin{abstract}
The relationship between drama and language learning is ever positive by virtue of all the benefits that it brings along. Shakespeare dramas are said to be very handy not only in giving insight into creative usage of English language but also an outreach platform for educators to strengthen their connectivity with students. Shakespeare theatrical performance has been recommended by the English teaching community to gain various benefits besides developing proficiency in English. As most learners in second language learning environment remain fearful about the classes as well as when interacting with their peers in and outside classroom, educators need to pay special attention towards the modality used in teaching and student engagement outside classroom.The survey of the audience conducted after the drama held in the form of performance lecture indicated high level of satisfaction among drama participants and their intention to participate in similar dramas as well as recommend to others who have not attended such dramas. Overwhelming support from students indicated that institutions can engage students using drama via lessons in classes. Workshops held based on performance lectures were also positively received. Conclusions and recommendations based on findings were also provided in support of drama usage for student engagement and language learning.
\end{abstract}

Keywords - Drama, English, performance lecture, language learning, literary techniques, Shakespearean, student engagement

\section{Introduction}

The Shakespeare Demystified: Othello Performance-Lecture (SDOPL), and Drama Acting Workshop (DAW) were delivered as an initiative by the English Language Centre (ELC) of the university in collaboration with student government body and the Shakespeare Drama Performers (SDP). Due to the success of its predecessor (Hamlet Performance-Lecture \& Workshop) in this university, the event came with higher expectations and anticipation, and a larger audience, for which it was held in the Grand Hall. The live performance of Shakespeare's Othello was first staged at the Kuala Lumpur Performing Arts Centre (KLPAC) and Penang Performing Arts Centre (Penang PAC) earlier this year, receiving positive reviews in both the Sun [1] and The Star newspapers [2].

Vikineswaran A. Maniam

Lisa Su Li Kwan

Hansini Thedchanamoorthy

Phawani Vijayaratnam

Daniel Tan Eng Keng

Lee Ling Sin

INTI International University

Malaysia
It is a long term initiative in engaging students by the university using various methods and platforms such sports, community service, field trips, educational projects and all sorts of competitions. In addition to these efforts, the ELC has worked fervently to bring an entertaining educational experience to students from various backgrounds in the university, college and schools within the vicinity using drama.

It is understandable that language learning becomes difficult at a certain age and in certain settings. Especially foreign or second language learning becomes a dilemma for the naive learners when they are into practicing that language daily. The problems faced by the learners, however, are incomparable with the hardships and difficulties encountered by the language teacher in teaching that particular language, for instance English. Hence, to enhance an English environment for students, adult learners and academicians, the SDOPL and DAW were organized as positive interventions.

By exposing students to literary performances students are made to understand the basics and complex structures of English language that can be challenging for the teachers. To make things easier, most of the teachers adopt certain techniques and methods and specialties of the English language and literature to make the language easy to learn. Different genres of English help students understand the English in an enhanced way and aid the learning capabilities as well. So, the importance of English drama cannot be ignored in this respect. The different techniques used in the drama help students understand English language in a laidback manner [3].

Drama aids the learners with effective and modernized way of learning English via communicative, active and contextualized manner it engages all the students in a recreational way and thus they absorb the details of language in a dynamic setting. Dramatization is the key to involve the students in improving all skills of the English language which are reading, listening, speaking and writing [4].

When it comes to drama writing, there is no more renowned a figure for this particular genre than William Shakespeare. The dramas have been translated into a myriad of languages. His dramas can be divided into different categories namely comedy, tragedy and history. The universality of Shakespeare is world acclaimed. The use of extensive and subtle vocabulary, varying styles and the description of human emotions cannot be better explained by any other writer than Shakespeare [5]. 
Incorporating the Shakespearean dramas such as the SDOPL in the undergraduate student learning environment provides great opportunity for appreciation of performance arts and drama amongst learners from diverse backgrounds. Performance lecture via Shakespeare drama in a tertiary education setting can prove an excellent choice because of its uniqueness and universality. The tone and context of the dramas facilitate the students into developing their accent and knowledge of the English language. Dialogue delivery and the body gestures are the cherry on the top which support the students in enhancing their language. However, teaching Shakespearean drama from the perspective of improving the language can prove hefty and challenging for many teachers. Additionally, the researchers' are investigating the claim that with the help of Shakespearean drama the English language learners are introduced to the English language creatively, they are engaged in a recreational manner as they read appropriate texts or literature, participate in performance lecture, drama acting workshops and also give presentations with extensive and sublime vocabulary, learners may take keen interest in the language.

\section{Research Objectives}

Generally, the objectives of this study were to investigate the language learning and engagement of the students and their benefits via Shakespearean dramas. The specific research objectives of this paper are to determine/describe:

(i) The perception of students on the overall performance by drama performers

(ii) Whether the students would prefer such dramas in the future

(iii) Whether students will recommend friends to participate in similar dramas in the future

(iv) Comments given by students upon attending the performance lecture, and

(v) Comments given by students upon participating in the drama acting workshop.

\section{Literature Review}

Drama means "any kind of activity where learners are asked either to portray themselves or to portray someone else in an imaginary situation" [6]. In other words, drama is concerned with the world of "let's pretend"; it asks the learner to project himself imaginatively into another situation, outside the classroom, or into the "skin and persona of another person". Drama activities and techniques in the teaching of language bring many positive outcomes. First of all it is entertaining and fun, and can provide motivation to learn in addition to varied opportunities for different uses of language. As drama engages feelings it can provide a rich experience of the language for the participants [7].

[8] listed many points in support of drama usage in the education field as follows: i. It integrates language skills in a natural way. Careful listening is a key feature. Spontaneous verbal expression is integral to most of the activities; and many of them require reading and writing, both as part of the input and the output.

ii. It integrates verbal and non-verbal aspects of communication, thus bringing together both mind and body, and restoring the balance between physical and intellectual aspects of learning.

iii. It draws upon both cognitive and affective domains, thus restoring the importance of feeling as well as thinking.

iv. By fully contextualizing the language, it brings the classroom interaction to life through an intensive focus on meaning.

v. The emphasis on whole-person learning and multisensory inputs helps learners to capitalize on their strength and to extend their range. In doing so, it offers unequalled opportunities for catering to learner differences.

vi. It fosters self-awareness (and awareness of others), self-esteem and confidence; and through this, motivation is developed.

vii. Motivation is likewise fostered and sustained through the variety and sense of expectancy generated by the activities.

viii. There is a transfer of responsibility for learning from teacher to learners which is where it belongs.

ix. It encourages an open, exploratory style of learning where creativity and the imagination are given scope to develop. This, in turn, promotes risktaking, which is an essential elements in effective language learning.

x. It has a positive effect on classroom dynamics and atmosphere, thus facilitating the formation of a bonded group, which learns together.

xi. It is an enjoyable experience.

xii. It is low-resource. For most of the time, all you need is a 'roomful of human beings'.

A study by [9] showed that when students were asked how often they participated in various activities within the area of Humanities Activities, "Attend a concert, dance performance or live drama" received the highest mean score (2.98 out of 5.0), while "Creating a painting, sculpture or other work of visual art" received the lowest (2.27).

Second language learning is not always about absorbing new lexical forms, phonological forms and rectification of the grammatical errors rather it is sometimes acquired to excel socially and to contend in the symbolically forwarding world, culturally. Such individuals have an intention for agency and a determination of striving. This discussion is backed up by the social constructionist and socio-historical theories which are still valid in the society. Rather than just correcting the mistakes and never repeating them the approach paves way to having accurate knowledge and utilizing it in the most effective way [10].

[11] came up with this theory of second language acquisition. According to him, language acquisition neither has the basis of using grammar in a very conscious way nor 
does it require any trainings or exercises. The people acquiring the second language are not concerned with the grammar they are using but rather the focus is mainly on the clear and accurate context being delivered in the message [12]. Hence, drama programs via performance lecture can be helpful in second language learning environment.

Language learning by participating in drama activity can be one of the most interesting and unique ways for language acquisition. Reading the text or giving a demonstrative act can improve the language. The aim is to choose such plays for representation or reading that can evoke the interest of the learners and help them expand their knowledge. By integrating dramas in the learning process, learning ability can be boosted and the attention of the students can be grabbed easily [13].

Shakespearean drama language has been scattered in different journals and books, and the learners who intend to have an in-depth study of Shakespearean language and style face many problems. Shakespearean language has great dedication and implication in the English history and students who want to improve their language tend to have a strong grip over his style and context. Shakespearean compilations present interesting texts, contexts, social and personal situations, cultural and historical differences and the tragic scenarios and aspects of humanity [14], that are extremely beneficial to critical thinking, vocabulary building and overall language learning.

\section{Methodology}

This research is a descriptive research based on a survey on participants of a performance lecture by SDP. The population $(\mathrm{N})$ is 380 and the sample (n) is 146 . The survey was administered via handouts during classes and also through a Google Drive link. There were 3 questions using a 10 point Likert scale ranging from $1=$ Highly Disagree to $10=$ Highly Agree and a fourth question using open-ended mode. This method of research was chosen to gauge students' responses to participation in the SDOPL. The survey questionnaire was designed to address the four research objectives. The items are listed in Table 1 below:

Table 1: Post-Event Survey Items

\begin{tabular}{|c|c|c|}
\hline No. & Item & Type \\
\hline 1 & $\begin{array}{r}\text { My level of satisfaction with the Othello } \\
\text { performance lecture is very high. }\end{array}$ & \multirow{2}{*}{$\begin{array}{c}\text { Close-ended } \\
\text { (10-point } \\
\text { scale: } 1- \\
\text { Highly } \\
\text { Disagree, } 10- \\
\text { Highly Agree) }\end{array}$} \\
\hline 2 & $\begin{array}{r}\text { I will attend similar shows organized by COLAL- } \\
\text { INTIMA in the future. }\end{array}$ & \multirow{2}{*}{ Open-ended } \\
\hline 4 & $\begin{array}{c}\text { I will definitely recommend my friends to attend } \\
\text { similar shows organized by COLAL-INTIMA in } \\
\text { the fure }\end{array}$ & \\
\hline
\end{tabular}

For the fifth research objective, simple survey questions were posed to seek respondent experience of the drama acting workshop. These were done separately and data was collected immediately after the drama.

Through the above methodology this research paper describes the advantages of drama integration in a second language learning environment involving local and international students. The benefits of the language and style being used in the context of drama will be speculated.

\section{v. Findings and Discussions}

\section{A. Audience Demographics}

Overall, there was an audience of 380 who attended the Othello performance, consisting of undergraduates, year 12 students and staff, and secondary school students. Students were from various programs including all Bachelor's degree programs, diploma programs and Foundation students. Others that were registered by courses were from Public Speaking, General Studies, and Introduction to Literature Appreciation (ILA), accompanied by their respective lecturers. Staff and academicians who attended included those from business and engineering faculty, and even Corporate. In addition, there were secondary school students comprising of students from nearby schools and children of staff. The school students and Introduction to Literature Appreciation were also involved in the workshops. Fig 1 summarizes the audience demographic profile for the SDOPL program participants.

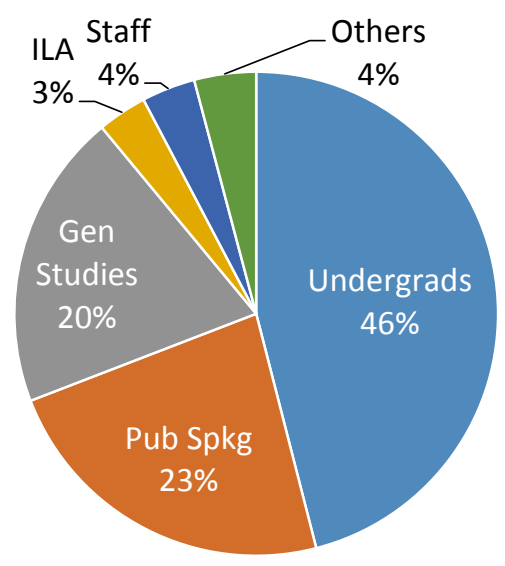

Figure 1: Breakdown of Audience Composition

\section{B. Research Objective 1: To determine the perception of students on the overall drama performance by SDP}

\author{
My level of satisfaction with the Othello \\ performance lecture is very good
}

The figures given vertically in the bar chart of Fig 2 indicate number of students and those on the horizontal 
show the response based on 10 point Likert scale. From Fig 2 above, $52.1 \%$ of the students were highly satisfied with the Othello performance-lecture (points
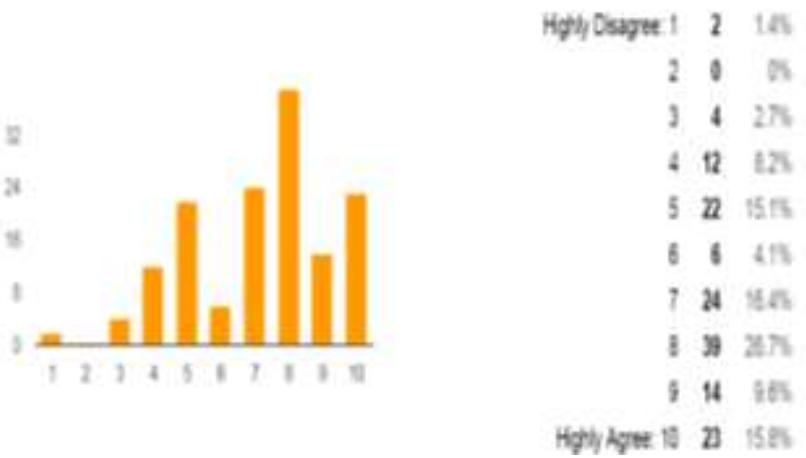

Figure 2: Analysis for Survey Item 1

8 and above), while only $4.1 \%$ disagreed (points 3 and below). Generally, students had a high level of satisfaction with the play. The average mean score was a high 7.2 $(n=146)$ on a scale of 10 . This was similar to previous finding by [9] that students' preference for drama sored a mean average of 2.98 on a scale of 5 . This indicated that students appreciated the benefits of drama as mentioned by [8] in that drama participation is an enjoyable experience.

\section{Research Objective 2: To determine students' preference for such drama in the future}

I will attend similar shows organized by the university in the future

Fig. 3 shows that $42.5 \%$ ( 8 and above) of the students indicated that they would attend similar shows that are organized by ELC and the student body in the future. On the other hand, $10.9 \%$ of them would likely not ( 3 and below). Overall, most students have shown an interest in attending

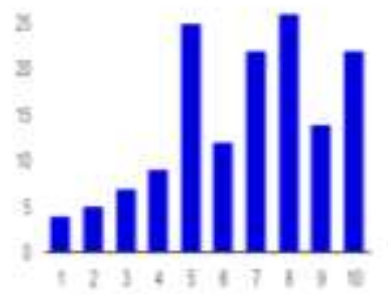

Figure 3: Analysis for Survey Item 2

similar shows like Othello should they be held in the university again. The mean score was 6.7 , indicating that students do appreciate the benefits of drama in their learning as espoused by [13] that integration of drama in the language learning process boosts learning ability and captures student attention that can augur well for student engagement by the university.
D. Research Objective 3: To determine whether students will recommend friends to participate in similar dramas in the future

I will definitely recommend my friends to attend similar shows organized in the future

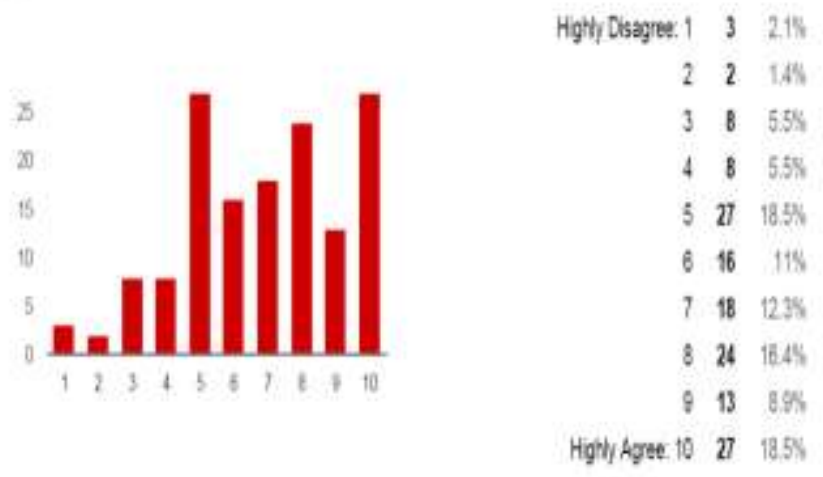

Figure 4: Analysis for Survey Item 3

Subsequent to their willingness to attend similar shows, similarly, $43.8 \%$ of the students would recommend their friends to attend such events. However, 9.0\% of the students said they would not. With the average mean of 6.8, generally this meant that students who enjoyed the show and wanted to watch more would definitely recommend these events to their friends, while those who did not would not. Hence, the results for this item in the survey was in tandem with the positive outcomes to the first research objectives above.

Furthermore, this finding was in line with the expectation of the university's management in that the SDOPL lived up to the success of its predecessor, Hamlet held in 2014. This SDOPL further affirmed [8] mention that students' motivation can be fostered and sustained through the variety and sense of expectancy generated by the activities of drama.

\section{E. Research Objective 4: Comments given by students upon participating in the drama}

Based on your answer to question 1 above write why you rate your satisfaction level as such

1. Their performance was very nice

2. The story was great but accent they were talking in is just too deep and it's a little bit hard for us to understand.

3. The story was interesting

4. It's not bad, but also not very good. It's normal in my opinion 
5. I like the way they expressed in the Othello drama, it is fantastic.

6. It is because it gained my knowledge regarding to English, and also, it is a way to show people how to talk a proper English and gained confident level.

7. Because it is difficult to do such an amazing play.

8. The show was well performed to us, i can understand the story through this performance

9. Throughout the show i didn't feel bored. It gives me the interest to read Shakespeare books as the play was very well played and easy to understand.

10. Some students could not understand what they were performing. it is only applicable to whom like this type of performance

11. The play was enjoyable, interesting, and fun

12. They use a very good vocabulary. Every of them were acting very well. overall, nice performance

13. It's very exciting

14. I gain the new experience.

15. I was just half satisfied with it.

16. The story line was interesting and intriguing but the English and accent is very deep, it was hard for me to catch

17. The show is realistic with great acting

18. The performance is very nice. There are many moral values we can learn.

\section{Figure 5: Analysis for Survey Item 4}

Generally, as per summary of comments given in Fig 5, students who felt positively about the show expressed that they were impressed with the story, the actors and the play as a whole. They also felt that it was interesting and "amazing", and that they learned language and presentation skills like pronunciation, facial expressions, and voice projection. It was a "great experience", and they were appreciative of the opportunity, requesting for "more exposure". Additionally, a drama of intellectual nature must be chosen so that it gives the learner an atmosphere full of fun and knowledge. Such a drama must be filled with emotions, varying settings and intensity so that the learners can get to know the true usage of language. The dramas by Shakespeare fulfill this condition but even at this point teachers face many problems as to how to incorporate the difficult language of Shakespeare in an effective way [15].

However, there was also some criticism mostly with regards to the Shakespearean language used in the play. Students found difficulty understanding as the actors were using "strong British slang", "extinct English terms", and "English language that is too profound". Nevertheless, the "action is very vivid" which aided comprehension. Others mentioned dissatisfaction with the clarity of sound and view from where they were seated, which indicates an issue with the acoustics and layout of the Grand Hall as the venue.

\section{F. Research Objective 5: Comments from the drama acting workshop participants}

The performance workshops were conducted by 2 facilitators from the drama organization. Therefore, there were 2 groups of workshop participants : one was open to interested students from nearby schools, and the other to the university students. All had attended the Othello performance-lecture held earlier.

The workshop included tips on standing postures, breathing techniques, voice projection, proper articulation, and body language through exercises, games and hands-on activities. Overall, students thoroughly enjoyed the sessions. Certificates of participation were later awarded to the school students.

Overall, the results of the survey showed that the majority of students who attended the performance enjoyed and gained much from it, and are looking forward to more of such events being organized as good exposure, entertainment as well as learning experience. For most of the researchers and analysts, English learning through drama has an efficient way for developing the sense of creativity in the naïve learners. It helps students in developing their intellect, problem solving skills, social instinct, communication, empathy and self-reliance.

With the myriads of emotional contexts and gestures specific to certain eras, language can be fathomed till its core. Moreover, drama provides ample opportunities to the learners to enhance their language skills through dialogue delivery and use of text in an exceptional way, an opportunity that is often not given to them in an English language class [4].

Studying Shakespeare in the English language class can be helpful for the students in great ways. With proper guidance and tricks it can be fathomed. Resultantly, students get trained in rehearsing their lines, memorizing difficult words and practicing different styles. The combined performance of the students helps them develop their communication skills and they learn to work in groups [16].

\section{vi. Conclusion}

From the experience of organizing the previous Hamlet event, several matters had been improved on. There was a longer duration for the planning and preparation process, and therefore, the event went very smoothly without a hitch, and achieved its objectives. This is demonstrated by the generally positive student feedback received whereby students mentioned that they were inspired and fascinated by the story, the actors, and the Shakespearean language. On top of that, the workshop participants also genuinely enjoyed themselves and felt that they gained some useful techniques to become better 
performers. All in all, Othello was an even better success than its predecessor, and hopefully, future similar events will be even more so.

It can be concluded that Shakespearean dramas are very effective in teaching English language to the students. The young minds cannot cope with the difficult structures of English language and sometimes they become distressed or lose interest in the studies due to the difficulty of the syllabus, so the best way to teach them the concepts of English literature is through the means of creative activities. Shakespearean plays are packed with the amazing manners of breakthrough literary techniques that increase the progress of the young learners and provide them a source of entertainment as well. Converting his dramas in the form of plays will serve as a fun learning activity and will help build up the confidence of the participants. They will be able to learn in an enhanced environment.

\section{Recommendations}

English is a fun language that, if learned with interest, can be helpful in many other fields of life. Based on the findings, similar dramas should be organized by the university to foster student engagement as it has many positive outcomes, including high intention of repeat participations and positive word of mouth advertising to entice other students to attend. Future drama organizers should reconsider the suitability of the venue, the Grand Hall for such performances. Drama can also be used to help students to improve critical thinking skills, personalities and cultural awareness. From the feedback received, it could be worth considering other performances of literary plays (not necessarily Shakespeare's) that use more modern, yet proper English. Further research is needed on how lecturers can be trained to teach drama in their English lessons. Perhaps the institution should explore including Shakespearean drama in non-language subjects for improving language and thinking skills.

\section{References}

[1] K. Arukesamy, "The Bard Demystified," The Star. Retrieved 26 April 2015, from http:// www. pressreader.com/malaysia/the-sun-malaysia/20150407/ 281998965971650/TextView, April 7, 2015.

[2] D. K. Maganathan, "Shakespeare Demystified's Othello: Got juice, but needs more seasoning," The Star. Retrieved 26 April 2015, from http://www. thestar.com.my/ Lifestyle/ Entertainment/ Arts/OnStage/ 2015/04/25/Shakespeare-Demystifieds-Othello/, April 25, 2015.

[3] L. Athiemoolam, "Drama-in-education and its effectiveness in English second/foreign language classes," In meeting of The First International
Language Learning Conference. Universiti Sains Malaysia, Penang, 2004.

[4] D. Albalawi, "Effectiveness of Teaching English Subject using Drama on the Development of Students' Creative Thinking," IOSR Journal of Research \& Method In Education (IOSRJRME), 4(6), 54-63. doi:10.9790/7388-04615463, 2014.

[5] Shakespeare-online.com, "Shakespeare's Plays," Retrieved $20 \quad$ August 2015, from http://www.shakespeare-online.com/plays/, 2015.

[6] S. Holden, Drama in Language Teaching. Longman, 1982.

[7] M. Zyoud, "Using drama activities and techniques to foster teaching English as a foreign anguage: A theoretical perspective," Retrieved 02 August 2015, http://www.qou.edu/ english/conferences/ firstNational Conference/pdfFiles/muntherZyoud.pdf. , 2010.

[8] A. Maley, and A. Duff, "Drama Techniques: A resource book of communication activities for language teachers," Cambridge: Cambridge University Press, 2005.

[9] A. Eggers, M. Tymms, and J. Coraggio, "Graduating Student Survey Report 2010 - 11.," St. Petersbug College . Retrieved 15 July 2015, from http://www.spcollege.edu/Central /Surveys / Surveys_Documents/ Graduating Student Survey Reports (Multiple Years) / GraduatingStudentSurvey2010-11.pdf., 2012.

[10] J. P. Lantolf, "Sociocultural theory and second language learning," Oxford University Press, 2000.

[11] S. Krashen, and T. Terrell, "The Natural approach: Language acquisition in the classroom," Prentice Hall International Ltd., 1988.

[12] Sk.com.br., "Stephen Krashen's Theory of Second Language Acquisition," Retrieved 20 August 2015, from http://www.sk.com.br/sk-krash-english.html, 2015.

[13] L. R. Rastelli, "Drama in language learning," Encuentro, 16, 82-94, 2006.

[14] V. Salmon, and E. Burness, (Eds.), "A reader in the language of Shakespearean drama," (Vol. 35). John Benjamins Publishing, 1987.

[15] C. Boudreault, "The benefits of using drama in the ESL/EFL classroom," The Internet TESL Journal, 16(1), 1-5, 2010.

[16] R. Farrelly, "Ross Farrelly: Why Study Shakespeare?" Rossfarrelly.blogspot.com. Retrieved 20 August 2015, from http://rossfarrelly.blogspot.com/2003/08/whystudy-shakespeare.html, 2003. 